Disponível em

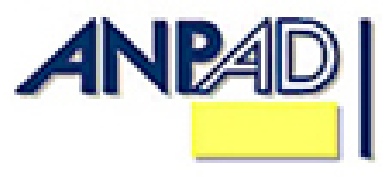

http://www.anpad.org.br/rac

RAC, Rio de Janeiro, v. 18, n. 1, art. 5,

pp. 78-95, Jan./Fev. 2014

$(\infty)$ EY-No

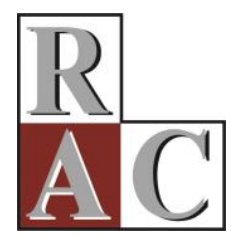

\title{
Trabalho, Violência e Sexualidade: Estudo de Lésbicas, Travestis e Transexuais
}

\section{Work, Violence and Sexuality: A Study of Lesbians, Transvestites and Transsexuals}

\begin{abstract}
Alexandre de Pádua Carrieri
E-mail: aguiar.paduacarrieri@terra.com.br

Universidade Federal de Minas Gerais - UFMG

FACE/UFMG, Av. Pres. Antônio Carlos, 6627, 31270-901, Belo Horizonte, MG, Brasil.

Eloisio Moulin de Souza

E-mail: eloisiomoulin@gmail.com Universidade Federal do Espírito Santo - UFES CCJE/UFES, Av. Fernando Ferrari, 514, Goiabeiras, 29075-910, Vitória, ES, Brasil.

Ana Rosa Camillo Aguiar E-mail: aguiar.paduacarrieri@terra.com.br Universidade Federal de Minas Gerais - NEOS/UFMG FACE/UFMG, Av. Pres. Antônio Carlos, 6627, 31270-901, Belo Horizonte, MG, Brasil.
\end{abstract}




\title{
Resumo
}

Este artigo estuda as violências simbólicas e interpessoais, vivenciadas na sociedade e no trabalho, dirigidas a lésbicas, travestis e transexuais. Contudo, para cumprir seu intento, foi preciso analisar as violências vivenciadas pelos sujeitos da pesquisa em seu contexto social mais amplo, envolvendo aspectos familiares, dentre outros, ampliando-se também a análise para além do trabalho formal. Foram entrevistados sessenta e cinco sujeitos, utilizando-se também a técnica de diário de campo para produção de dados. A análise foi realizada por meio da técnica de Análise Crítica do Discurso (ACD), utilizando-se Fairclough (1992, 1995) como principal referência para análise. Conclui-se que os entrevistados sofrem diversas formas de violência simbólica, fruto das dominações simbólicas que se instauram de forma particular em cada um dos grupos estudados. As violências interpessoais vivenciadas no trabalho têm relações estreitas com as formas de violências simbólicas relacionadas a cada grupo, e ocorrem com maior intensidade contra os travestis, pois estão mais propensos e sujeitos a sofrerem violência interpessoal por meio de agressões físicas, fato que coloca em risco a integridade física e a vida dos travestis.

Palavras-chave: violência; trabalho; lésbicas; travestis; transexuais.

\begin{abstract}
This article studies the interpersonal and symbolic violence experienced at work directed at lesbians, transvestites and transsexuals. However, to accomplish its purpose, we had to analyze the violence experienced by the subjects in their broader social context, involving family issues, among others; extending the analysis beyond the formal work environment. Sixty-five subjects were interviewed, using the field diary technique to produce data. Analysis was performed via Critical Discourse Analysis (CDA), with Fairclough (1992, 1995) adopted as the main approach. We conclude that respondents suffer various forms of symbolic violence, the fruit of symbolic domination, which are established in a particular way in each of the groups studied. The interpersonal violence experienced at work is closely related to the forms of symbolic violence related to each group, and occur with greater intensity for transvestites because they are more likely to suffer from and be subject to interpersonal violence through physical aggression, a fact that puts their physical integrity and lives at risk.
\end{abstract}

Key words: violence; work; lesbians; transvestites; transsexuals. 


\section{Introdução}

O objetivo do presente artigo $^{(1)}$ é analisar as violências simbólicas e interpessoais vivenciadas por lésbicas, travestis e transexuais - respectivamente na sociedade e no trabalho. Entendemos que as violências relacionadas ao trabalho não se encontram desconectadas da realidade social em que os sujeitos se inserem e que muitas vezes estas violências têm suas raízes na e pela ordem social estabelecida. Assim, o estudo não se limitou ao ambiente laborativo, mas abordou as outras instâncias da vida dos sujeitos.

Calás e Smirchich (1999) defendem a expansão epistemológica dos estudos organizacionais, buscando com este projeto epistemológico expandir o estudo de diversos temas. Nesse sentido, vale ressaltar que, principalmente em relação às diferenças produzidas sobre a sexualidade, os estudos organizacionais brasileiros têm muito que avançar nesta expansão, pelo fato de que a maioria dos trabalhos sobre o tema está relacionado a gays (Carrieri, 2006; Garcia \& Souza, 2010; Irigaray, 2007; Siqueira, Saraiva, Carrieri, Lima, \& Andrade, 2009), havendo ainda poucos trabalhos sobre lésbicas (Irigaray \& Freitas, 2011) e transgêneros (Bicalho \& Caproni, 2012).

Além de expandir o campo para o estudo de travestis e transexuais, salienta-se que o movimento de Lésbicas, Gays, Bissexuais e Transgêneros (LGBTs) não é um grupo homogêneo, em que muitos transexuais, travestis e lésbicas não se sentem ouvidos ou incluídos no mesmo (Namaste, 2006). Assim, dar voz a esses sujeitos e mostrar as particularidades e as diferenças de cada um desses grupos em relação à violência vivida na sociedade e no trabalho é algo necessário.

Antes de tudo, deve-se ressaltar que a pesquisa não teve uma trajetória fácil. O caminho foi árduo. As formas de violência instauradas em nossa sociedade são muitas. A normalidade, ou o que é dito normal e aceito como tal, faz com que vários grupos sejam excluídos e vistos como sendo anormais, abjetos, em função de seus corpos (Souza \& Carrieri, 2010; Thanem, 2003). Nesse sentido, Miskolci $(2009$, p. 162) afirma que existe em nossa sociedade "um processo normalizador que cria seres considerados menos humanos, em suma, abjetos". O problema ainda mais grave está quando o tema da sexualidade se instaura, pois, como nos diz Foucault $(1979,1985)$, neste século XX, muito se fala sobre sexo, mas pouco se permite sobre o exercício do mesmo.

O estudo que nos propusemos a executar possuiu, além disso, a pertinência de responder a demanda apresentada por Prado e Machado (2008, p. 119), na qual afirmam a necessidade de que "pesquisas científicas busquem compreender com mais precisão como a articulação de hierarquias que geram subalternização de grupos sociais se entrelaça, sobrepõe-se e cria formas de opressão e violência que, apesar de todo o sofrimento que causam, permanecem ocultadas".

Assim, serão apresentados a seguir os principais conceitos relacionados à sexualidade, bem como as pesquisas realizadas nos estudos organizacionais sobre o tema que têm relação com o objetivo deste artigo. Posteriormente realizaremos um debate sobre violência interpessoal e simbólica. Em seguida, serão apresentados os caminhos percorridos para se realizar esta pesquisa. Por fim, são expostas as análises dos discursos e as principais conclusões.

\section{A Sexualidade e os Estudos Organizacionais}

Prado e Machado (2008) apontam que as transformações dos discursos sobre a sexualidade tornaram possíveis a ressignificação da sexualidade humana, provocando uma desnaturalização, desessencialização e desbiologização da sexualidade, permitindo que elementos fundamentais da sustentação do preconceito social e da legitimação fossem questionados. Lentamente, os sujeitos que eram até então completamente excluídos das preocupações da sociedade capitalista conservadora passaram a ser seu alvo de interesse, uma vez que se mostraram potenciais consumidores e 
trabalhadores com perfil desejado. As relações homoeróticas, por exemplo, tornam-se então exóticas aos olhos de parte da sociedade, sendo até mesmo incorporadas em campanhas de merchandising. "A diferença nesses casos, é instigadora, é merchandising: é o diferente exibido como curiosidade, como exceção, o que de fato serve para reforçar a norma" (Navarro-Swain, 2000, p. 65).

Para Tauches (2006), sexualidades são construções sociais. A visão de construção social da sexualidade distingue-se das noções essencialistas de sexualidade. A visão essencialista enxerga sexualidade como algo natural, ou seja, enfatiza a heterossexualidade como algo normal e superior, considerando as demais formas de sexualidades como desviantes e inferiores. A autora afirma que a sexualidade pode ser vista tanto como um ato (comportamento) quanto como uma identidade. Como comportamento, a sexualidade é entendida como um ato que pode ser valorizado e/ou desvalorizado em uma determinada sociedade, mas que não é considerada como uma identidade que definiria um tipo específico de ser humano (Weeks, 2006). Somente a partir do século dezoito é que a sexualidade passou a ser considerada como uma identidade e não mais como um comportamento (Weeks, 2006). Contudo, não devemos entender aqui identidade como algo estático e homogêneo. Conforme Plantenga (2004) salienta, identidade deve ser entendida como fragmentada e múltipla, pois mesmo minorias têm suas identidades interconectadas com outras máscaras identitárias e frequentemente desafiam as estruturas opressivas e quebram as dicotomias.

Vista como identidade, a sexualidade opera tanto no nível pessoal, interpessoal e institucional (Tauches, 2006). No nível pessoal, a sociedade dita o que é considerado normal para uma pessoa em termos de identidade de gênero e sexualidade, reforçando as categorias socialmente construídas, fazendo com que o sujeito sinta-se coagido a enxergar-se e classificar-se como pertencendo a uma determinada categoria. No nível interpessoal, quando duas pessoas interagem, aparência, comportamento, gestos, corpo e normas sociais atuam de forma conjunta para criar atribuições e categorias fundamentadas no gênero e na sexualidade. Por fim, no nível institucional, gênero e sexualidade são organizados em uma hierarquia, na qual homens, masculinidade e heterossexualidade são valorizados em relação a mulheres, feminilidade e homossexualidade (Tauches, 2006).

Em relação a essas categorizações, a definição da orientação sexual lesbiana para Mott (2000) transcende a especificidade das relações eróticas que são estabelecidas, sem excluí-las enquanto indicação de mulheres adeptas a práticas sexuais com outras mulheres, envolvendo identidade, afirmação, estilo de vida e projeto civilizatório alternativo, o qual ele denomina de cultura homossexual. Já travestis promovem modificações nas formas de seu corpo visando deixá-lo o mais parecido possível com o das mulheres; vestem-se e vivem cotidianamente como pessoas pertencentes ao gênero feminino sem, no entanto, desejar explicitamente recorrer a cirurgia de transgenitalização para retirar o pênis (Benedetti, 2005, p. 18). Por fim, os transexuais reivindicam a "cirurgia de mudança de sexo como condição sine qua non da sua transformação, sem a qual permaneceriam em sofrimento e desajuste subjetivo e social" (Benedetti, 2005, p. 18).

Para Namaste (2006), transexuais são indivíduos que nascem em um sexo, mas que se identificam como membro do sexo oposto, tomam hormônios e submetem-se a intervenções cirúrgicas para remodelar a genitália. Contudo, transgêneros para a autora é um termo mais abrangente que inclui todas as formas de pessoas que não se ajustam nas relações normativas entre sexo e gênero como drag queens, transexuais e travestis. Observa-se que as pesquisas anglo-saxônicas consideram o travestismo como uma questão de gênero e não apenas de sexualidade (Colgan \& McKearney, 2012; Muhr \& Sullivan, 2013; Namaste, 2006). Contudo, Kulick (1997), ao estudar travestis brasileiros, verificou que os travestis estudados consideram a sexualidade, ao invés de gênero, o principal elemento constituidor de suas identidades.

Pode-se observar que o processo de exclusão social dessas categorias não opera da mesma forma, o que torna ainda mais complexa a união de todas essas categorias em um único movimento e sigla (LGBTs). Por exemplo, de acordo com Carvalho (1995), a homossexualidade masculina passa a não expressar mais um critério determinante para exclusão social do ponto de vista do consumo. Aliás, conforme apregoado por Carrieri (2008), em decorrência de empenho superior, associado à maior flexibilidade de horários e à possibilidade de realocação entre as sedes das empresas, por não 
possuírem vínculos matrimoniais e filhos como limitadores, a inserção de sujeitos não heterossexuais no ambiente de negócios tem sido interpretada como desejável por um número crescente de gestores.

No entanto, conforme apregoam Galeão-Silva e Alves (2002), a política de diversidade sexual, que tinha como intuito combater o preconceito sexual dentro da gestão das organizações, não se efetivou em plenitude, porquanto a discriminação encontra-se enraizada no campo das ideias e se expressa mesmo quando se fita extingui-la. Souza, Silva e Carrieri (2012) e Irigaray (2007) afirmam que a diversidade existe de fato apenas nos discursos e não nas práticas empresariais.

A gestão da diversidade emergiu como uma resposta das organizações para capitalizarem vantagem competitiva (Metcalfe \& Woodhams, 2012). Embora a gestão de diversidade seja apresentada com o rótulo inclusivo, estudiosos (Braidotti, 1994; Fraser \& Nicholson, 1988; Metcalfe \& Woodhams, 2012) sentem que a diversidade nessa perspectiva é usada apenas como um significante despolitizado, em que a justiça social é suprimida por discursos de vantagem competitiva, performance e lucro, chegando-se ao ponto, por exemplo, de autores como Hayes, Bartle e Major (2002) criarem modelos para se gerir a diversidade. Contudo, Herring e Henderson (2011) salientam que esses modelos de gestão de diversidade não são efetivos na redução de níveis de desigualdades e inclusão.

Isso demonstra que há na literatura uma considerável disparidade entre pesquisadores sobre a definição de inclusão. Pelled, Ledford e Mohrman (1999) definem inclusão como o grau pelo qual empregados são tratados como insiders pelos outros trabalhadores. Mor Barak (1999) afirma que a percepção do empregado sobre inclusão-exclusão é um processo contínuo no grau de sentimentos individuais que inclui acesso a informação e recursos, conectividade com superiores e colegas de trabalho, e habilidade para participar e influenciar o processo de tomada de decisão. Alinhados com a perspectiva da gestão da diversidade, Holvino, Ferdman e Merril-Sands (2004) definem organizações inclusivas aquelas em que diversidade de conhecimento e perspectivas dos membros pertencentes a diferentes grupos são trazidos para a organização e modelam sua estratégia, seu trabalho, sua gestão, sua operação de sistemas, seus valores e normas para o sucesso.

Adotamos neste artigo a perspectiva de diversidade crítica, perspectiva esta oposta à gestão de diversidade. Zanoni, Janssens, Benschop e Nkomo (2010) afirmam que existem diversas teorias que fazem parte das abordagens críticas de diversidade: pós-estruturalismo, análise do discurso, estudos culturais, pós-colonialismo e teoria institucional. Contudo, o que essas teorias têm em comum é a contestação da visão instrumental da diferença, compartilhando um entendimento não positivista e não essencialista de diversidade, enfatizando a construção de identidades como socialmente (re)produzidas em um processo contínuo e específico. Herring e Henderson (2011) acrescentam que a diversidade crítica é mais do que abraçar diferenças culturais que existem entre grupos ou apreciar essas diferenças, pois preocupa-se com questões relacionadas a paridade, equidade e inequidade em todas suas formas, ou seja, confronta questões de opressão e estratificação que revestem a diversidade. Para Herring e Henderson (2011, p. 632, tradução nossa), "Uma teoria de diversidade crítica inclui um análise da exclusão, discriminação". Todo processo de exclusão/inclusão opera por meio de relações de poder, relações estas que também se manifestam por meio de violências dirigidas a um determinado grupo.

\section{Violência Simbólica e Interpessoal}

Bicalho (2008, p. 12) aponta que "uma violação pontual, seja ela física ou discursiva, pode impactar de maneira mais perniciosa para o sujeito do que pequenas violências sucessivas, cabendo ao próprio avaliar aquilo que mais o vitimiza, ou seja, fá-lo sentir violentado". Catley (2005) afirma que a violência não se manifesta apenas por meio de agressões físicas, defendendo uma leitura atenta às violências estruturais que caracterizam o cotidiano dos ambientes de trabalho contemporâneos. Tornase importante uma abordagem que não se limite ao plano das relações de trabalho quando tratamos de 
aspectos que envolvem o preconceito, como é o caso desta proposta de estudo, tendo em vista que os "sofrimentos individuais podem ter suas raízes na estrutura social do preconceito" (Prado \& Machado, 2008, p. 76).

Vale salientar que preconceito são quaisquer formas de "percepções mentais negativas em face de indivíduos e de grupos socialmente inferiorizados, bem como as representações sociais conectadas a tais percepções" (Rios, 2007, pp. 27-28). A expressão discriminação significa a "materialização, no plano concreto das relações sociais, de atitudes arbitrárias, comissivas ou omissivas, relacionadas ao preconceito" (Rios, 2007, p. 28). As discriminações se materializam na forma de violências interpessoais.

Adotamos duas vertentes para abordar a violência na sociedade e no trabalho: interpessoal e simbólica. Ao fazermos o estudo das violências interpessoal e simbólica, estamos realizando uma análise de dois diferentes níveis de violência. Enquanto a violência interpessoal está focada para as relações que acontecem nas interações entre sujeitos no nível micro social, a violência simbólica busca entender o nível macro social. Contudo, os níveis micro e macro social de análise estão interconectados e são interdependentes. Sobre este aspecto Holgate et al. (2012) enfatizam a importância de se utilizar diferentes níveis de análise quando estamos analisando as inequidades vivenciadas por minorias.

Violência interpessoal pode ser entendida através do conceito apregoado por Bicalho (2008, p. 12): "decorre do ato de agredir o sujeito física ou discursivamente em seu ambiente de trabalho, impactando de modo degradante em questões atinentes ao seu trabalho, à sua vida pessoal e às suas relações; com destaque para as implicações psicopatológicas". Lavigne e Bourbonnais (2010) definem violência interpessoal no trabalho como formas de intimidação: uso de ameaças, assédio, comportamento vexatório, comentários verbais, ações ou gestos hostis ou indesejados que afetam a dignidade ou a integridade psicológica.

O trabalho de Lavigne e Bourbonnais (2010) é um dos poucos estudos internacionais que analisam a violência interpessoal no trabalho. Já nos estudos organizacionais brasileiros, destacam-se os trabalhos de Rosa, Brito e Oliveira (2007) e Lopes, Bicalho, Gandra e Diniz (2009). A pesquisa realizada por Rosa et al. (2007) estudou aspectos de gênero relacionados às diversas formas de violência, inclusive interpessoais, vivenciadas por uma policial militar no trabalho. Lopes et al. (2009) analisaram a violência sofrida no trabalho por homossexuais masculinos, contudo, as autoras consideram violência interpessoal como significando o mesmo que assédio moral apenas.

A segunda vertente de violência fundamenta-se no conceito elaborado por Bourdieu (2007) sobre violência simbólica. As formas e as significações que o sujeito dá à sua realidade não são consideradas inquestionáveis, afastando-se de sua existência como sendo natural, mas como uma construção sócio-histórica. Construindo e legitimando esta leitura naturalizada do mundo, encontramos o exercício do poder simbólico.

O poder simbólico erige a realidade através da instituição de uma ordem gnosiológica, isto é, de uma significação imediata para o mundo, em especial para o mundo social, bem como impõe e legitima significações através de esquemas de percepção e disposições incorporados pelos sujeitos. Ademais, o poder simbólico é exercido, unicamente, com a cooperação e a conivência daqueles sujeitos que lhe são subordinados, uma vez que eles o constroem como um poder real, aderindo à lógica discursiva que impulsiona a integração moral e que, consequentemente, possibilita a construção e a reprodução do consenso acerca da ordem social instituída.

Em decorrência do exercício do poder simbólico, temos a violência simbólica, a qual se estabelece "por meio de um ato de cognição e de mau reconhecimento que fica além - ou aquém - do controle da consciência e da vontade, nas trevas dos esquemas de habitus que são ao mesmo tempo generados e generantes" (Bourdieu, 1998, pp. 22-23). Para Rosa et al. (2007), a violência simbólica opera de forma sutil, praticamente invisível, impondo uma relação de subjugação-submissão e de cumplicidade do subjugado. Dessa forma, segundo Rosa et al. (2007), a violência simbólica depende 
da cumplicidade de quem a vivencia e a sofre. Essa naturalização da violência simbólica na ordem social é evidenciada por Alcadipani (2010) ao estudar a relação entre violência simbólica relacionada à masculinidade e, por Carrieri, Aguiar e Diniz (2013), ao analisarem a violência simbólica direcionada a homossexuais.

Retornando às ideias originais de Bourdieu (2003, pp. 7-8), apreende-se que a violência simbólica é uma "violência suave, insensível, invisível as suas próprias vítimas". Destarte, a dominação simbólica se instaura através de um processo sustentado pela existência e pelo reforço de pensamentos e predisposições alinhados às estruturas impostas, refletindo em ações de conhecimento, reconhecimento e submissão ao instituído por parte dos dominados, que julgando autoevidente tal processo, não conseguem romper com o mesmo, conspirando para a sua própria dominação (Bourdieu, 1975, 1998, 2003).

Esse sistema de dominação marcado pela violência simbólica se institucionaliza e se reproduz graças à construção sócio-histórica da desigualdade e da exclusão, por meio de instituições específicas, tais como a Família, a Igreja, a Escola e o Estado (Bonnewitz, 2003; Bourdieu, 1975, 1996, 2003). O preconceito que caracteriza a exclusão daqueles que se distanciam do padrão de normalidade social é talvez a manifestação mais insidiosa da violência simbólica e fundamenta-se no paradoxo que define tal violência, impedindo-nos de ver o que não vemos, ou seja, impossibilita ao sujeito identificar os limites de sua própria percepção da realidade, "atua ocultando razões que justificam determinadas formas de interiorizações históricas, naturalizadas por seus mecanismos" (Prado \& Machado, p. 67).

Butler (2010) denomina de matriz heterossexual os modelos discursivos/epistemológicos hegemônicos de inteligibilidade de gênero que afirma que, para os corpos terem coerência e fazerem sentido, têm que existir um sexo estável que se expressa através de um gênero também estável (masculino expressa macho, e feminino, a fêmea), que são opostos e hierarquicamente definidos por meio de uma prática compulsória de heterossexualidade.

\section{Caminhos Percorridos}

Intentou-se desenvolver esta pesquisa com sujeitos que trabalhem, formal ou informalmente, nas quatro capitais do sudeste brasileiro: Belo Horizonte, São Paulo, Rio de Janeiro e Vitória. Os sujeitos que compõem o grupo de interesse para estudo da pesquisa proposta são: lésbicas, travestis e transexuais. Para descrever a metodologia da pesquisa, são apresentados a seguir a metodologia e a técnica de pesquisa empregada, seguidos pelo procedimento de análise dos dados. Destacamos que o desenvolvimento da pesquisa se propõe a apreender as duas categorias de violências expressas nas categorias analíticas descritas no referencial teórico: interpessoal e simbólica.

A pesquisa proposta foi desenvolvida a partir de uma metodologia qualitativa, visto ser esta, segundo González-Rey (2005), uma via para a construção de modelos teóricos de inteligibilidade durante o estudo de realidades que não são acessíveis de maneira direta, nem em sua organização, nem em seus processos. A pesquisa qualitativa "fornece uma compreensão profunda de certos fenômenos sociais apoiados no pressuposto da maior relevância do aspecto subjetivo da ação social face à configuração das estruturas societais" (Haguette, 2003, p. 63).

A operacionalização do campo da pesquisa proposta envolveu, primeiramente, o contato com associações de reunião e apoio a homossexuais, especificamente lésbicas, travestis, e transexuais, em cada uma das quatro capitais do sudeste brasileiro, tais como o grupo Centro de Luta pela Livre Orientação Sexual de Minas Gerais (CELLOS-MG) e a Associação Lésbica de Minas (ALEM). Enfatizamos a existência de uma predisposição dos responsáveis por estas entidades em nos auxiliar com tal pesquisa. 
Com o intuito de delimitar a seleção dos sujeitos de pesquisa, utilizou-se o método bola de neve (Gil, 1995; Gray, Williamson, \& Karp, 2007), segundo o qual a seleção seria construída ao longo do processo de pesquisa por meio de indicações dos próprios sujeitos de pesquisa. Essa escolha é considerada por Thiollent (1987) como desígnio de um reduzido número de pessoas que possuam informações relevantes em relação ao tema estudado.

Previa-se que todas as entrevistas fossem gravadas e até mesmo filmadas. Contudo, a violência por qual passam os sujeitos que participaram dessa pesquisa nos fez mudar as estratégias metodológicas. Assim, coletamos entrevistas gravadas quando foi possível, atingindo o total de 30 entrevistas coletadas, sendo a maioria de lésbicas. Dessas, 30 filmamos, sendo 02 entrevistas com travestis. Mas o grosso de nossos dados advém de entrevistas não gravadas, mas anotadas em diários de campo, obtendo-se 35 entrevistas, principalmente de transgêneros. Esse grupo foi o mais arredio à proposta de pesquisa. Todas as entrevistas foram conduzidas por um roteiro semiestruturado, gravadas e transcritas ou anotadas nos diários de campo, sendo este último procedimento desenvolvido com o cuidado de resguardar a reprodução fiel dos discursos, evitando cortes e acréscimos (Alberti, 2004; Meihy, 1996; Neves, 2001). O roteiro usado foi desenvolvido com a participação de grupos focais de 06 lésbicas, 06 travestis e 06 transexuais, todos separados, sendo que os dados obtidos não foram incluídos como parte da produção de dados. Fizemos reuniões em que os sujeitos narraram suas histórias de vidas, principalmente com o foco no trabalho (Gaskell, 2002). Após o tratamento dos dados, os sujeitos foram nomeados de E1 a E65, buscando resguardar suas identidades sexuais e manter sigilosamente qualquer indício que pudesse identificá-los. Ao se interpretar os discursos pelo uso da Análise Crítica do Discurso (ACD), somos influenciados pelas demandas do tempo vivido e vivenciado, e sempre fazemos reinterpretações. Além disso, precisa-se entender que todo discurso é também uma prática social. O discurso é uma prática de significação do mundo, constituindo e construindo o mundo em significados (Fairclough, 1992, 1995). Como prática social, ele pode construir o mundo tanto de forma convencional assegurando a reprodução da sociedade, quanto de forma criativa buscando a transformação da sociedade. Fairclough (1995) afirma que, pelos efeitos construtivos do discurso, pode-se evidenciar as identidades sociais e as posições de sujeitos; as relações sociais estabelecidas entre as pessoas; e os sistemas de conhecimento, crenças e visões de mundo.

Segundo Alvesson e Karreman (2000), Hardy (2001), Fairclough (1992), Phillips e Hardy (2002) e Mumby (2004), há várias abordagens da AD e estas desenvolvem propostas distintas para as análises dos discursos. A tradição anglo-saxã de ACD privilegia a oralidade, a sociologia e os estudos etnometodológicos, cujo caráter é mais empirista, tendo influência da Escola de Frankfurt, assim como de Bourdieu, sendo Fairclough o seu teórico principal. Para Fairclough (1992), o sujeito é ao mesmo tempo agente-assujeitado. Nesse sentido, como as estruturas e as práticas dos sujeitos se revelam plásticas, e essa plasticidade recoloca o sujeito, ora motivado intencionalmente, ora determinado ideologicamente. Ainda no sentido de trabalhar com a ACD, toma-se de Fairclough $(1992,1995)$ sua proposta analítica, composta de três dimensões: (a) a primeira, começando do micro: onde apareceriam as estratégias de persuasão: (aa) a construção das personagens no discurso e sua relação com as personagens efetivamente existentes; (ab) a seleção lexical, isto é, a escolha do vocabulário usado nos discursos; (ac) as relações entre os conteúdos explícitos e os implícitos, que possibilitam criar um efeito ideológico de sentido; (ad) o silêncio sobre determinados temas, ou seja, aquilo que não é dito. A (b) segunda (meso), a dimensão das práticas discursivas: intertextualidade (há a manifesta - clara disposição do discurso, marcada por aspas; e há a pressuposta - relaciona-se aos pressupostos implícitos tomados como tácitos pelos sujeitos); interdiscursividade; coerência textual; presença e ausência de elementos (silêncios). A (c) terceira dimensão é a das práticas sociais. É na prática social, segundo Fairclough (1992, 1995), que os níveis macro e micro se aglutinam, ou seja, este autor enfatiza que as práticas diárias sociais podem ser observadas nas falas sobre o cotidiano, a vida e a trajetória dos sujeitos, e isso poderia ser analisado pelo níveis macro e micro do discurso. É pelas práticas sociais, pelo histórico das práticas, das trajetórias dos sujeitos e a construção de suas práticas que a ACD deveria caminhar, buscando somar os níveis macro e micro de análise. RodriguesJúnior (2009), fazendo uma crítica da ACD, nos diz que nossa leitura deveria sempre privilegiar a construção histórica das relações sociais do mundo cotidiano. Nesse sentido, optamos por enfatizar 
neste artigo a violência simbólica (nível macro) e a violência interpessoal (nível micro) na construção das histórias de vida e do trabalho dos sujeitos participantes desta pesquisa.

\section{A História de Vida e o Trabalho: Diferenças e Violências}

No espaço que se segue, trouxemos as interpretações das várias entrevistas que fizemos. São vários relatos contando da vida, do trabalho, da (in)diferença e das diversas violências vividas pelos sujeitos que entrevistamos. Primeiramente começaremos a analisar a violência simbólica para, em seguida, abordar a violência interpessoal.

\section{Violência simbólica: matriz heterossexual binária de gênero}

Devemos entender que existe uma matriz heterossexual (Butler, 2010) que atua de forma compulsória, constituindo não somente o que é normal, mas também as identidades e as possibilidades de existência do que pode ser considerado anormal. Além disso, devemos considerar que o poder simbólico se materializa sobre os sujeitos por meio de violência simbólica (Bourdieu, 1975, 2003).

Em relação à violência simbólica, vale ressaltar que a dominação simbólica se instaura através de um processo sustentado pela existência e pelo reforço de pensamentos e predisposições alinhados às estruturas impostas, refletindo em submissão ao instituído por parte dos dominados, que não conseguem romper com o mesmo, conspirando para a sua própria dominação (Bourdieu, 1975, 1998, 2003).

Ao analisarmos os discursos das lésbicas as mesmas evidenciam que, apesar de se sentirem diferente desde cedo, elas não conseguem romper com o modelo reprodutivo heterossexual, procurando ajustarem-se as estruturas sociais da matriz heterossexual, conforme E1 e E08 salientam: "desde cedo eu já sabia que eu tinha uma opção sexual diferente. E isso foi crescendo ao longo da minha vida... e apesar de ter me casado aos 19 anos". E08 fala que é "da tradicional família, criada para trabalhar e casar e ter filhos, ... seguir esse caminho mais normal (risos). Então, casei, tive dois filhos".

Passar primeiramente pela experiência do casamento heterossexual e constituírem famílias com filhos são discursos recorrentes nas entrevistas com lésbicas. É o que elas denominaram de uma criação tradicional e mais normal (Carvalho, 1995). Bourdieu (1975, 1996, 2003) salienta que o sistema de dominação marcado pela violência simbólica se institucionaliza e se reproduz graças à construção sócio-histórica por meio de instituições como a família e a religião. Nesse sentido, a obrigação imposta pelas famílias para que as entrevistadas se casem e tenham filhos manifesta uma violência simbólica na qual elas sentem-se coagidas e obrigadas a se ajustarem ao que é considerado normal. Elas são forçadas a se inserirem na matriz heterossexual, mesmo quando sentem desde cedo que são diferentes em relação a essa matriz.

Contudo, essa violência simbólica vivenciada pelas entrevistadas instaurou-se como uma "violência suave, insensível, invisível" (Bourdieu, 2003, pp. 7-8), pois a dominação simbólica se instaura pelo reforço de pensamentos que estejam alinhados às estruturas impostas, manifestando-se em suas ações e submissões a matriz reprodutiva heterossexual, fazendo com que elas mesmas contribuam para sua dominação. $\mathrm{O}$ rompimento com a dominação e a violência simbólica vivenciada pelas lésbicas ocorre posteriormente, quando estão em idade mais adulta e não se sentem mais obrigadas a seguir o modelo heterossexual: "Não tenho que optar pelo heterossexualismo quando na verdade não sinto nada e faço jus disso por nem ter conseguido ficar casada com uma pessoa, no caso o pai do meu filho. E querendo ou não eu não me sentia bem, estava empurrando uma relação" (E04).

É ao sair da relação heterossexual que a identidade sexual de ser lésbica é aceita por elas. O tema da identidade que aparece nas falas das lésbicas traz a metáfora da Entendida, conforme E1 e 
E10 respectivamente enfatizam: "Eu sou entendida" e "O que quer dizer? (Risos). Quer dizer que eu entendo de mulher".

Conforme E09 evidencia, a religião é uma instituição que também atua nesse processo de normalização de acordo com a matriz heterossexual reprodutiva: "Foi e é difícil, não sei, mas tem a ver com a religião, sabe? Minha família não me aceita bem, ficam falando que não é normal, que Deus criou a mulher para o homem e não a mulher para a mulher (risos)". E5 acrescenta que "No início tive medo de encarar essa realidade até pela minha família ser evangélica e tudo". Para Foucault (1979, 1985), na sociedade moderna, o sexo se reduziria à sua função reprodutora, e o casal passa a ser o modelo. Ele nos diz que foi o poder que incitou a proliferação de discursos sobre o sexo através da igreja, da escola, da família, do consultório médico, dentre outros. Essas instituições não visavam proibir ou reduzir a prática sexual; visavam ao controle do indivíduo e da população.

Em relação aos transexuais, a violência simbólica instaura-se pelo corpo, pois "Ser transexual não é nada fácil. Você fica se olhando no espelho e deseja ser outro ou outra. Ter outra identidade. É muito sofrido mesmo" (E40). Os transexuais sentem que seus corpos não se ajustam à identidade de gênero a que gostariam de pertencer. E38 afirma que "você chega, olha no espelho e fala assim; não dá para continuar, não sou eu essa pessoa que está na frente do espelho, não sou eu, e se vê horrível". $\mathrm{O}$ modelo binário de gênero estabelece o padrão de corpo para homens e mulheres, fazendo com que os transexuais busquem ajustar seus corpos de acordo com esse modelo, pois enxergam esse modelo como natural e como a única possibilidade de construção dos corpos, não visualizando alternativas de construção de seus corpos que esteja fora desse modelo.

Para os transexuais, toda pessoa que tem atributos e traços femininos necessita ter o corpo de mulher, e quem tem traços masculinos necessita ajustar seu corpo ao de um homem, conforme E24 afirma: "Eu sempre quis mudar de sexo, nunca quis ficar num meio termo, né, que, no caso, seria o travesti". Os transexuais não problematizam gênero e entendem gênero como um aspecto biológico, determinado pelo corpo físico, em que masculino e feminino são coisas opostas e excludentes. Para o grupo de transexuais, a mudança se concretiza com a operação. Para alguns entrevistados, ser transexual e não submeter-se à operação de mudança de sexo é, por si só, uma violência, pois ficaria em um meio termo. Ao buscarem normalizarem seus corpos ao modelo binário de gênero, os transexuais reforçam e alimentam ainda mais esse modelo, contribuindo ativamente com a mesma dominação simbólica que os violenta.

É pela incorporação e naturalização do modelo binário de gênero que a violência simbólica atua nos transexuais. Sobre esse aspecto, E24 afirma que "Nossa, é assim ... horrível, porque eu sabia que eu era desde muito nova, né, ... e sabia que eu não me sentia bem sendo homem". A esses processos de naturalização e incorporação do modelo hegemônico de inteligibilidade de gênero, Butler (2010) denomina matriz heterossexual, na qual, para os corpos terem coerência e fazerem sentido, deve existir um sexo estável que se expressa através de um gênero também estável.

Ao compararmos as lésbicas e os transexuais, podemos afirmar que a violência simbólica instaura-se no nível pessoal de lésbicas e transexuais quando a dominação simbólica dita o que é considerado normal em termos de identidade de gênero e sexualidade, fazendo com que lésbicas e transexuais reforcem as categorias socialmente construídas, coagindo-os a classificarem-se e a ajustarem-se em uma destas categorias (Tauches, 2006).

Assim como os transexuais, os travestis também demonstraram uma forte relação com o corpo. Contudo, esta relação se estabelece de uma forma bem específica e diferente. Ao invés de procurarem normalizar e ajustar seus corpos de acordo com o modelo binário de gênero, os travestis querem fugir desse modelo. Em outras palavras, os travestis não querem seguir os modelos de gênero e colocam em cheque a matriz heterossexual e o modelo binário de gênero: "Então eu sou mais dessa proposta de ser diferente e valorizar isso porque se eu for operar, eu tô normatizando, eu tô querendo ser, ... eu tô normatizando a minha diferença né?" (E17). Diferentemente do grupo de transexuais que apontam a operação de mudança total do corpo como o mais importante, travestis evidenciam que a não operação 
e a manutenção do órgão sexual mostra uma diferença, e que a opção de retirá-lo normalizaria o corpo segundo os padrões de gênero.

Contudo, tal fato torna seus corpos mais propensos a serem considerados como abjetos (Thanem, 2003), pois não se encaixam na ordem corporal estabelecida (Miskolci, 2009). Assim, a violência simbólica opera nos travestis quando seus corpos são considerados monstrous bodies, ou seja, abjetos. Com as mudanças que realizam no corpo, os travestis não têm como esconder sua condição de travesti, tornando-se mais vulneráveis à violência simbólica: "Agora a travesti, ... ela tá ali naquela ... entre a marginalidade sabe? Mesmo ela não querendo estar ali, ela não tem oportunidade pra sair dali.... A transexual não é eu acho que a transexual se engloba bem, a $d r a g$ se engloba bem, gay, lésbica, tudo isso enquadra bem” (E18).

Exatamente por não buscarem se encaixarem na matriz heterossexual binária de gênero, os travestis sofrem violência simbólica. Entretanto, diferente das lésbicas e transexuais, não nos parece que os travestis contribuem para a reprodução e a manutenção dessa matriz. Entretanto, não escapam da violência simbólica, pois, por não contribuírem com a matriz heterossexual binária de gênero, os travestis são os que mais sofrem violências, ou seja, a contribuição que as lésbicas e os transexuais realizam para manutenção da matriz heterossexual binária de gênero faz com que fiquem menos expostos à violência simbólica. Contribuir para a manutenção da matriz que oprime é uma forma de atenuar a violência simbólica, mas não de eliminá-la: "Homossexual continua vestido de homem ou de mulher, então, a sociedade engole mais fácil, aceita melhor. Agora a travesti não, que a transformação dela é meio que agride o sistema de alguma forma” (E34).

Dessa forma, podemos concluir que travesti é uma forma específica de gênero: o gênero travesti. Este processo de construção do corpo fora das normas estabelecidas é denominado pelos travestis de montagem, conforme E20 e E21 exemplificam: "Por exemplo, eu me montei bem nova e me achei bonita, eu gostei de mim montada" (E20), pois "A mudança ocorre na montagem" (E21).

\section{Trabalho e violências interpessoais}

Para Bicalho (2008), a violência interpessoal decorre de agressão física ou discursiva no ambiente de trabalho. Lavigne e Bourgonnais (2010) ampliam esse conceito de violência interpessoal no trabalho afirmando que ela se manifesta por meio de intimidações, ameaças, assédio, comentários, ações ou gestos que são hostis ou indesejados, não limitando o conceito apenas a agressão física ou discursiva. Como a violência interpessoal ocorre através da interação com outras pessoas, é nesse processo de interação que aparência, comportamento, gestos, corpos e normas sociais atuam de forma conjunta para criar categorias fundamentadas em gênero e sexualidade (Tauches, 2006).

Os discursos chamam atenção pelo fato de evidenciarem a discriminação no trabalho, o medo da diferença e a normalidade estabelecida: "as pessoas é ... de empresas ... querem uma pessoa normal para trabalhar para eles". Existe uma estreita relação entre violência simbólica e interpessoal, ressaltando-se que a violência simbólica opera no nível macro, e a interpessoal, no nível micro.

Para algumas lésbicas, várias são as formas de violência por qual passam, buscando não revelar sua identidade homossexual. E1 expõe essa violência na hora de arrumar trabalho: "Eu sofro violência pra trabalhar. Eu já tive que deixar o cabelo crescer, eu tenho que andar feminina. Eu gosto de andar masculina". Além disso, E12 demonstra que essa violência foi incorporada e (re)produzida (Bourdieu, 1975, 1998, 2003), pois ela aceita e incorpora esse "limite para você agir, para você se comportar dentro de uma empresa". Aliás, o medo de perder o trabalho ou sofrer retaliações faz com que a maioria das entrevistas assuma um comportamento socialmente feminino de gênero: "No trabalho eu tenho medo de sofrer retaliações, eu prefiro não me expor".

E12 traz também questões relacionadas ao relacionamento interpessoal com os clientes no trabalho: "Infelizmente as pessoas têm preconceito, e você vai colocar um homossexual... menos discreta para atender o público, aí pode ser até um problema para a empresa". Tal fato revela a incorporação do matriz heterossexual inclusive pelas lésbicas entrevistadas e, consequentemente, a 
existência de preconceito e discriminação entre os próprios homossexuais para com os que mais se afastam do atributo de normalidade heteronormativa (Garcia \& Souza, 2010).

O "silêncio" (E7), o "discreto e o não atrito" (E9) revelam facetas do medo de se expor, de tornar visível uma identidade sexual não heterossexual. Ser discreto torna-se algo estrategicamente importante para ser contratado e manter-se no trabalho. E11 relata que, ao realizar entrevistas para seleção de pessoas, "foi feita uma entrevista com um rapaz, só que ele era muito afeminado, ... sugeri, mas meu chefe achou ele muito afeminado". E14 evidencia formas de violência interpessoal associadas à baixa escolaridade de algumas lésbicas como justificativa para a não aceitação no trabalho de sua condição homoafetiva.

Particularmente, muitas formas de violências interpessoais são vivenciadas por meio de piadas ou uso de palavras que tenham conotação desqualificadora (Lavigne \& Bourgonnais, 2010). E7 fala que é comum usarem o vocábulo sapatão: "Ela tava implicando comigo, eu perguntei o porquê, ela falou que odeia sapatão, né" (E7). Muitas das entrevistadas evidenciam as piadas como formas de violência. E1 salienta: "É ... brincadeira, é, risinho assim, né. É comentário". E6 ressalta o uso de palavras ríspidas: "Um cliente ... sabia que eu era homossexual e teve uma atitude um pouco agressiva .... foi muito desagradável".

Algumas lésbicas até consideram a existência de uma barreira invisível em relação ao crescimento na carreira (Garcia \& Souza, 2010). Nesse aspecto, E13 afirma que substituiu "a chefia, mas eu não conseguia ascender dentro da empresa, eu não conseguia ser promovida, ... essa barreira estava posta por ser negra e homossexual". A condição racial associada à homossexualidade torna mais difícil ainda a promoção no trabalho.

Para os travestis, a busca por um trabalho formal é bem mais difícil, pois o fato de serem considerados abjetos os torna mais vulneráveis às violências interpessoais. E34 é enfática sobre isto: "o mercado de trabalho não dá oportunidade, você já é discriminado já de cara, quando você vai entregar o currículo o povo nem recebe seu currículo", pois "é uma dificuldade muito grande, demais mesmo" (E19).

Os travestis tentam conseguir trabalho formal, mas logo desistem em função da violência interpessoal que sofrem. $O$ fato dos travestis não se encaixarem e nem buscarem se ajustar ao que a matriz heterossexual binária de gênero (Butler) constitui como normal, faz com que eles sejam mais sujeitos a atos de violência interpessoal, pois passam a ser considerados e vistos como não humanos e tratados como objetos (Thanem, 2003). Para os travestis, a invisibilidade é algo impossível. Por constituírem um gênero específico, sua condição de travesti marca o corpo e não possibilita ocultação e invisibilidade.

Assim, a primeira violência interpessoal que os travestis sofrem é exatamente o fato de serem tratados como destituídos de humanidade. Quando vão à procura de emprego, os travestis não são considerados pelos profissionais como um recurso humano para o trabalho: "a travesti é muito inteligente, ele é capaz de muita coisa, entendeu? Ela não é um bicho, ela não é um monstro, que a gente é tachada como analfabeta, como um Zé Ninguém," (E18).

A decepção e a violência interpessoal vivida na busca por emprego formal marcam os travestis. E16 afirma que "Sempre busquei trabalho, sempre tentei arrumar um trampo qualquer, com carteira assinada e tudo mais. É uma tarefa elefantíase". E34 evidencia que não existe a mínima possibilidade de um travesti conseguir emprego formal: "É ai vem a questão do mercado de trabalho, o mercado de trabalho não dá oportunidade, você já é discriminado já de cara, quando você vai entregar o currículo, o povo nem recebe seu currículo tá entendendo". Como não conseguem trabalho formal, a primeira alternativa de trabalho para os travestis é a prostituição: "Eles não ti dão nem a chance e aí a opção que tem é a prostituição, não tem outra porque ou você prostitui ou você morre literalmente de fome, de miséria e de tudo" (E33).

Diferentemente das lésbicas e transexuais, os travestis foram os únicos a relatarem que a violência interpessoal sofrida não se limita apenas a intimidações, ameaças pessoais, assédio, 
comentários verbais, preconceito, ações e gestos hostis, pois a violência interpessoal que mais os incomoda no seu trabalho na rua se manifesta na forma de violência física. A violência interpessoal dirigida a travestis atinge seu estágio máximo e consolida-se por meio de agressões físicas graves (Bicalho, 2008): "Você entra no carro, que você não conhece a pessoa, você sabe nem se você volta. Entende? E ainda ter entre nós, desavenças por coisas assim que não teria necessidade" (E21).

Como não são considerados humanos por grande parte de seus clientes, estes clientes tratam os travestis como objetos e não veem problema algum em agredi-los fisicamente. São apenas brinquedos e objetos sexuais nas mãos dos mesmos. No trabalho, o travesti "não sabe o que vai passar, o que vai acontecer. Às vezes, você entra num carro, se vai voltar, então assim é uma vida muita arriscada. A gente está numa esquina, a gente está sujeita a tomar um tiro, a tomar uma pedrada” (E16).

Os travestis relatam diversas formas e níveis de agressões físicas sofridas. Têm "pessoas que jogam latas de cervejas do carro, jogam pedra e tudo" (E20). Jogar objetos nos travestis para feri-los é algo rotineiro na vida dos entrevistados: "Pedrada nas ruas, meninos passando no ônibus ..., jogam pedra, garrafa, daquela long neck" (E39). A violência interpessoal acontece também por meio de xingamentos e pelo fato de considerá-los como lixo social e objeto descartável: "Palavras, chamam de desgraça, essas palavras pesadas, diz que a gente vai morrer ..., passam em carro e jogam lanche de MC Donalds misturado com ketchup, essas coisas" (E39).

O interessante é que, por conviverem de forma frequente com essas formas de violência interpessoal, os travestis acabam se acostumando com essa realidade, incorporando essas violências em seus atos, agindo de forma violenta inclusive com seus pares: "Então, é assim, durante o dia, a gente conversa, ri, brinca. Mas, a noite é como se dizer, não falo inimiga, mas uma competindo com outra entendeu?" (E16).

Quanto aos transexuais, a busca de trabalho produz outras possibilidades que não a prostituição. Os discursos mostram uma dificuldade de se conseguir empregos, mas há também fragmentos que revelam uma mudança nesse aspecto. Essa maior facilidade de conseguir emprego é devido à normalização que os transexuais operam em seus corpos, ajustando-os ao modelo binário de gênero, reafirmando, dessa maneira, gênero como algo estável que se relaciona diretamente com um corpo também estável. Contudo, essa facilidade só acontece se mantiverem invisível sua condição de transexual. Portanto, diferentemente dos travestis, os transexuais podem tornar invisível sua condição de transgêneros, já que não apresentam antagonismo entre gênero e corpo.

Por isso, uma das violências interpessoais que alguns transexuais percebem é o antagonismo existente entre o nome contido na carteira de identidade e o corpo feminino que apresentam. Se não fosse essa contradição, os transexuais estariam revestidos pelo manto da invisibilidade, pois normatizaram e ajustaram seus corpos aos padrões fixos, opostos e excludentes de gênero. $\mathrm{O}$ nome masculino em seus documentos os tira dessa invisibilidade, denunciando sua condição de transexual, colocando-os novamente como anormais: "Antigamente eu mandava meu currículo com meu nome de registro ... e aí chegava uma pessoa completamente diferente. Aí as pessoas tomavam um choque assim, um susto" (E54).

Quando não estão protegidos pela invisibilidade, os transexuais sofrem discriminação na contratação e atuação profissional, conforme afirma E22: "Bom, se eu for trabalhar numa empresa ... acham que a gente vai prejudicar por ser gay ou ser travesti ou transexual". E61 salienta que foi "chamado para fazer estágio na empresa X e eles não me aceitaram". E50 também enuncia que trabalhou "na XYZ ... tinha aquela coisa assim ... nossa, uma transexual, ela é minha monitora, eu não quero a orientação dela". A visibilidade da dupla identidade, social e de nascimento, prejudica os transexuais na busca e no exercício do trabalho.

Vários transexuais afirmaram que, quando revelam sua condição, sofrem violências interpessoais no trabalho por meio de piadas. Por exemplo, E57 salienta que "Quando eu trabalhei numa empresa... sempre surge piadinha, isso e aquilo". E30 utiliza a estratégia de fazer vista grossa 
para lidar com esta forma de violência interpessoal: "Sempre surge piadinha, isso e aquilo, mas... eu procurei abstrair, relevar, deixar para lá porque a pessoa não sabe o que tá falando".

Os discursos expõem que a principal alternativa de trabalho para os transexuais é o concurso público: "No meio privado é muito ruim, mas no meio público a gente ainda tem chance. Sabe, num concurso, a gente é um número" (E45). Contudo, conseguir um emprego público não livra completamente o transexual da discriminação, pois eles não conseguem ser promovidos, conforme E25, por exemplo, revela: "Se passa no concurso, as pessoas têm que aceitar. Claro que depois a gente sofre (risos), no meu caso nunca fui promovida".

\section{Considerações Finais}

O objetivo deste artigo foi analisar a vivência simbólica e interpessoal de lésbicas, transexuais e travestis. A violência simbólica está diretamente relacionada com a matriz heterossexual binária de gênero, na qual a normalidade é estabelecida como heterossexual e fundada em um gênero binário, constituído por apenas duas possibilidades opostas e excludentes entre si: masculino versus feminino.

As violências simbólicas e interpessoais não atuam da mesma forma entre os LGBTs. A dominação simbólica funciona e se estabelece de forma bastante específica em cada uma das identidades sexuais estudadas, produzindo violências simbólicas específicas direcionadas a lésbicas, transexuais e travestis. A violência interpessoal vivida no trabalho pelas lésbicas, travestis e transexuais estudados também demonstrou que existem diversas particularidades entre eles. Para lésbicas e travestis, existe a possibilidade de emprego formal, algo que para os travestis é impossível. O nome social ainda é uma questão mal compreendida ou não respeitada por muitos, e sua não adoção serve como munição para muitos homofóbicos. Ressaltamos a reprodução da violência simbólica no meio LGBTs, no qual o indivíduo não heterossexual, mesmo sendo alvo da violência simbólica, reproduz o ponto de vista da sociedade heteronormativa, de forma acrítica e não reflexiva. Dessa forma, as pesquisas que estudam LGBTs devem ter em mente que, apesar de estarem representados em uma única sigla, existem diversas particularidades e diferenças entre e dentro das identidades lésbicas, gays, bissexuais e transgêneros.

Consideramos que a construção da identidade dos travestis tem maior relação com questões de gênero do que com sexualidade. Apesar de muitos travestis atribuírem a sexualidade como determinante para construção de suas identidades, isso ocorre devido a necessitarem se prostituir para viver desde muito cedo. Mas, de fato, as grandes questões que afetam suas constituições identitárias estão estreitamente relacionadas a gênero, fazendo, inclusive, que possam ser considerados como um gênero específico.

Ainda chama atenção do grupo de pesquisadores, e também professores (de Administração), o tema da educação, mais precisamente da educação e da diferença, como se essas fossem causas da não aceitação em alguns lugares de trabalho da condição homoafetiva. Assim, cabe a nós, educadores (de Administração), trazer o tema da diferença, seja ela qual for, para ser debatido, discutido e explicitado nas salas de aula, a fim de produzir mudança e para que o diferente não seja tão diferente assim.

Concluímos o artigo com a sugestão e demanda de pesquisas futuras que contemplem os sujeitos de pesquisa que estudamos, pois escassas são as pesquisas a eles dirigidas, seja na área de estudos organizacionais ou em outras ciências sociais. Ademais, seria pertinente a replicação deste estudo em outras cidades e regiões brasileiras, para que se pudesse compreender a realidade de trabalho desse grupo social tão discriminado e marginalizado. Observamos nos relatos dos entrevistados que o corpo é um fator importante no processo de busca identitária, principalmente dos travestis e transexuais, contudo, as relações entre corpo e trabalho, bem como estudos sobre embodiment, têm sido pouco exploradas nos estudos organizacionais. 


\section{Nota}

${ }^{1}$ Pesquisa financiada pelo Conselho Nacional de Desenvolvimento Científico e Tecnológico (CNPq).

\section{Referências}

Alberti, V. (2004). Manual de história oral (2a ed.). Rio de Janeiro: Editora FGV.

Alcadipani, R. (2010). Violência e masculinidade nas relações de trabalho: imagens do campo em pesquisa etnográfica. Cadernos EBAPE.BR, 8(1), 93-110. doi: 10.1590/S167939512010000100007

Alvesson, M., \& Karreman, D. (2000). Varieties of discourse: on the study of organizations through discourse analysis. Human Relations, 53(9), 1125-1149. doi: 10.1177/0018726700539002

Benedetti, M. (2005). Toda feita: o corpo e o gênero das travestis. Rio de Janeiro: Garamond.

Bicalho, R. A. (2008, maio). Categorias Frankfurteanas para uma tipologia da violência nas organizações. Anais do Encontro de Estudos Organizacionais, Belo Horizonte, MG, Brasil, 5.

Bicalho, R. A., \& Caproni, H. L., Neto (2012, setembro). Análise das violências simbólicas vivenciadas por indivíduos transgêneros. Anais Encontro da Associação Nacional de PósGraduação e Pesquisa em Administração, Rio de Janeiro, RJ, Brasil, 36.

Bonnewitz, P. (2003). Primeiras lições sobre a sociologia de P. Bourdieu. Petrópolis: Vozes.

Bourdieu, P. (1975). A reprodução: elementos para uma teoria do sistema de ensino. Rio de Janeiro: Livraria Francisco Alves.

Bourdieu, P. (1996). Razões prática: sobre a teoria da ação (4a ed.). Campinas: Papirus.

Bourdieu, P. (1998). Conferência do prêmio Goffman: a dominação masculina revisitada. In D. Lins (Org.), A dominação masculina revisitada (pp. 34-68). Campinas: Papirus.

Bourdieu, P. (2003). A dominação masculina (3a ed.). Rio de Janeiro: Bertrand Brasil.

Bourdieu, P. (2007). O poder simbólico (10a ed.). Rios de Janeiro: Bertrand Brasil.

Braidotti, R. (1994). Nomadic subjects: embodiment and sexual difference in contemporary feminist theory. New York: Columbia University Press.

Butler, J. (2010). Problemas de gênero: feminismo e subversão da identidade. Rio de Janeiro: Civilização Brasileira.

Calás, M. B., \& Smircich, L. (1999). Past postmodernism? Reflections and tentative directions. Academy of Management Review, 24(4), 649-671. doi: 10.2307/259347

Carrieri, A. P. de (2006). Formas de assédio moral na trajetória profissional de trabalhadores homossexuais masculinos: um estudo em capitais do Brasil (Relatório de Pesquisa/2006), Belo Horizonte, MG, Universidade Federal de Minas Gerais.

Carrieri, A. P. de (2008). Formas de assédio moral na trajetória profissional de trabalhadores homossexuais masculinos: um estudo em capitais do Brasil (Relatório de Pesquisa/2008), Belo Horizonte, BH, Núcleo de Estudos de Organizações e Sociedade, Centro de Pós-graduação em Administração, Universidade Federal de Minas Gerais. 
Carrieri, A. P. de, Aguiar, A. R. C., \& Diniz, A. P. R. (2013). Reflexões sobre o indivíduo desejante e o sofrimento no trabalho: o assédio moral, a violência simbólica e o movimento homossexual. Cadernos EBAPE.BR, 11(1), 165-180. doi: 10.1590/S1679-39512013000100011

Carvalho, T. T. de (1995). Caminhos do desejo: uma abordagem antropológica das relações homoeróticas femininas em Belo Horizonte (Dissertação de mestrado). Universidade Estadual de Campinas, Campinas, SP, Brasil.

Catley, B. (2005, July). Workplace violence and the forging of management and organization history. Proceedings of the International Critical Management Studies Conference, University of Cambridge, Cambridge, 4.

Colgan, F., \& McKearney, A. (2012). Visibility and voice in organisations: lesbian, gay, bisexual and transgendered employee networks. Equality, Diversity and Inclusion, 31(4), 359-378. doi: $10.1108 / 02610151211223049$

Fairclough, N. (1992). Discurso e mudança social. Brasília: Editora UNB.

Fairclough, N. (1995). Media discurse. London: Edward Arnold.

Foucault, M. (1979). História da sexualidade I: a vontade de saber (2a ed.). Rio de Janeiro: Graal.

Foucault, M. (1985). A história da sexualidade III: o cuidado de si. Rio de Janeiro: Graal.

Fraser, N., \& Nicholson, L. (1988). Social criticism without philosophy: an encounter between feminism and postmodernism. Theory, Culture \& Society, 5(2), 373-394. doi: $10.1177 / 0263276488005002009$

Galeão-Silva, L. G., \& Alves, M. A. (2002, maio). A crítica do conceito de diversidade nas organizações. Anais do Encontro de Estudos Organizacionais, Recife, PE, Brasil, 2.

Garcia, A., \& Souza, E. M. (2010). Sexualidade e trabalho: estudo sobre a discriminação de homossexuais masculinos no setor bancário. Revista de Administração Pública, 44(6), 13531377. doi 10.1590/S0034-76122010000600005

Gaskell, G. (2002). Entrevistas individuais e grupais. In M. Bauer \& G. Gaskell (Orgs.), Pesquisa qualitativa com texto, imagem e som: um manual prático (pp. 64-89). Petrópolis: Vozes.

Gil, A. C. (1995). Métodos e técnicas de pesquisa social (4a ed.). São Paulo: Atlas.

González-Rey, F. (2005). Pesquisa qualitativa e subjetividade: os processos de construção da informação. São Paulo: Thomson.

Gray, P. S., Williamson, J. B., \& Karp, D. A. (2007). The research imagination: an introduction to qualitative and quantitative methods. Cambridge: Cambridge University Press.

Haguette, T. M. F. (2003). Metodologias qualitativas na sociologia (9a ed.). Petrópolis: Vozes.

Hardy, C. (2001). Researching organizational discourse. Studies of Management Organizations, 31(3), $25-47$.

Hayes, B. C., Bartle, S. A., \& Major, D. A. (2002). Climate for opportunity: a conceptual model. Human Resource Management Review, 12(3), 445-468. doi: 10.1016/S1053-4822(02)00050-5

Herring, C., \& Henderson, L. (2011). From affirmative action to diversity: toward a critical diversity perspective. Critical Sociology, 38(5), 629-643. doi: 10.1177/0896920511402701 
Holgate, J., Abbott, S., Kamenou, N., Kinge, J., Parker, J., Sayce, S., Sinclair, J., \& Williams, L. (2012). Equality and diversity in employment relations: do we practice what we preach? Equality, Diversity and Inclusion, 31(4), 323-339. doi: 10.1108/02610151211223021

Holvino, E., Ferdman, B. M., \& Merrill-Sands, D. (2004). Creating and sustaining diversity and inclusion in organizations: strategies and approaches. In M. S. Stockdale \& F. J. Crosby (Eds.), The psychology and management of workplace diversity (pp. 245-276). Malden: Blackwell.

Irigaray, H. A. R. (2007, setembro). Políticas de diversidade nas organizações: uma questão de discurso? Anais Encontro da Associação Nacional de Pós-Graduação e Pesquisa em Administração, Rio de Janeiro, RJ, Brasil, 31.

Irigaray, H. A. R., \& Freitas, M. E. (2011). Sexualidade e organizações: estudo sobre lésbicas no ambiente de trabalho. Organizações \& Sociedade, 18(59), 625-641. doi: 10.1590/S198492302011000400004

Kulick, D. (1997). Travesti. Chicago: Chicago University Press.

Lavigne, E., \& Bourbonnais, R. (2010). Psychosocial work environment, interpersonal violence at work and psychotropic drug use among correctional officers. International Journal of Law and Psychiatry, 33(2), 122-129. doi: 10.1016/j.ijlp.2009.12.005

Lopes, F. T., Bicalho, R. A., Gandra, G., \& Diniz, A. P. R. (2009, novembro). Além do assédio moral nas organizações: formas de violência interpessoal sofridas por trabalhadores homossexuais masculinos. Anais Encontro de Gestão de Pessoas e Relações de Trabalho, Curitiba, PR, Brasil, 2.

Meihy, J. C. S. B. (1996). Manual de história oral. São Paulo: Edições Loyola.

Metcalfe, B. D., \& Woodhams, C. (2012). Introduction: new directions in gender, diversity and organization theorizing - re-imagining feminist post-colonialism, transnationalism and geographies of power. International Journal of Management Review, 14(2), 123-140. doi: $10.1111 / \mathrm{j} .1468-2370.2012 .00336 . \mathrm{x}$

Miskolci, R. (2009). A teoria queer e a sociologia: o desafio de uma analítica da normalização. Sociologias, 11(21), 150-182.

Mor Barak, M. E. (1999). Beyond affirmative action: toward a model of diversity and organizational inclusion. Administration in Social Work, 23(3/4), 47-68. doi: 10.1300/J147v23n03_04

Mott, L. (2000). Em defesa do homossexual. Boletim informativo ILGA-LAC. Recuperado de http://www.dhnet.org.br/direitos/militantes/luizmott/mott1.html

Muhr, S. L., \& Sullivan, K. R. (2013). "None so queer as folk": gendered expectations and transgressive bodies in leadership. Leadership, 9(3), 416-435. doi: 10.1177/1742715013485857

Mumby, D. (2004). Discourse, power and ideology: unpacking the critical approach. In D. Grant, C. Hardy, C. Oswick, \& L. Putnam. (Eds.), The sage handbook of organizational discourse (pp. 237-258). London: Sage.

Namaste, V. (2006). Transsexual, transgender, and queer. In S. Seidman, N. Fischer, \& C. Meeks (Eds.), Handbook of the new sexuality studies (pp. 180-187). New York: Routledge.

Navarro-Swain, T. (2000). O que é lesbianismo. São Paulo: Brasiliense.

Neves, L. A. (2001, março). Ensaio metodológico - Memória e história: potencialidades da história oral [Texto adaptado de palestra proferida pela autora]. Anais do Encontro de História e III Encontro Nordeste de História Oral, Universidade Federal de Piaú, Teresina, PI, Brasil, 1. 
Pelled, L. H., Ledford, G. E., \& Mohrman, S. A. (1999). Demographic dissimilarity and workplace inclusion. Journal of Management Studies, 36(7), 1013-1031. doi: 10.1111/1467-6486.00168

Phillips, N., \& Hardy, C. (2002). Discourse analysis: investigating processes of social construction. Thousand Oaks, CA: Sage.

Plantenga, D. (2004). Gender, identity, and diversity: learning from insights gained in transformative gender training. Gender and Development, 12(1), 40-46. doi: 10.1080/13552070410001726506

Prado, M. A. M., \& Machado, F. V. (2008). Preconceito contra homossexualidades: a hierarquia da invisibilidade. São Paulo: Cortez.

Rios, R. R. (2007). O conceito de homofobia na perspectiva dos direitos humanos e no contexto dos estudos sobre preconceito e discriminação. In F. Pocahy (Org.), Rompendo o silêncio: homofobia e heterossexismo na sociedade contemporânea (pp. 27-48). Porto Alegre: Nuances.

Rodrigues-Júnior, A. S. (2009). Análise crítica do discurso: modismo, teoria ou método? Revista Brasileira Linguística Aplicada, 9(1), 99-132.

Rosa, A. R., Brito, M. J., \& Oliveira, F. M. (2007). Os sentidos da violência nas organizações: uma análise construcionista da história de vida de uma policial militar. Gestão e Sociedade, 1(1), 130 .

Siqueira, M. V. S., Saraiva, L. A., Carrieri, A. P., Lima, H., \& Andrade, A. (2009). Homofobia e violência moral no trabalho no Distrito Federal. Organizações \& Sociedade, 16(50), 447-461.

Souza, E. M., \& Carrieri, A. P. (2010). A analítica queer e seu rompimento com a concepção binária de gênero. Revista de Administração Mackenzie, 11(3), 46-70. Recuperado de http://www.scielo.br/pdf/ram/v11n3/a05v11n3.pdf. doi: 10.1590/S1678-69712010000300005

Souza, E. M., Silva, A. R. L., \& Carrieri, A. P. (2012). Uma análise sobre as políticas de diversidade promovidas por bancos. Psicologia \& Sociedade, 24(2), 315-326. doi: 10.1590/S010271822012000200009

Tauches, K. (2006). Transgendering: challenging the "normal". In S. Seidman, N. Fischer, \& C. Meeks (Eds.), Handbook of the new sexuality studies (pp. 173-179). New York: Routledge.

Thanem, T. (2003). Contested and monstrous bodies. Ephemera: Critical Dialogues on Organization, $3(3), 250-259$.

Thiollent, M. J. M. (1987). Crítica metodológica, investigação social e enquete operária. São Paulo: Polis.

Weeks, J. (2006). The social construction of sexuality. In S. Seidman, N. Fischer, \& C. Meeks (Eds.), Handbook of the new sexuality studies (pp. 14-20). New York: Routledge.

Zanoni, P., Janssens, M., Benschop, Y., \& Nkomo, S. (2010). Unpacking diversity, grasping inequality: rethinking difference through critical perspectives. Organization, 17(1), 9-29. doi: $10.1177 / 1350508409350344$ 